\title{
Correlation between Lgr5 Expression and 5-FU based Chemotherapy Response in Stage IV Colorectal Cancer Patients
}

\section{Kgs. M. Rosyidi ${ }^{1}$, Mediarty Syahrir ${ }^{*}$, Suly Auline Rusminan ${ }^{2}$, Legiran $^{3}$}

${ }^{1}$ Division Hematology and Oncology, Department of Internal Medicine, Faculty of Medicine, Universitas Sriwijaya, Palembang, Indonesia

2Department of Anatomical Pathology, Faculty of Medicine, Universitas Sriwijaya, Palembang, Indonesia

${ }^{3}$ Department of Anatomy, Faculty of Medicine, Universitas Sriwijaya, Palembang, Indonesia

\section{A R T I C L E I N F O}

Keywords:

Lgr5 expression

chemotheray responses

colorectal cancer

*Corresponding author:

Mediarty Syahrir

E-mail address:

medi_sy@yahoo.com

All authors have reviewed and approved the final version of the manuscript.

https://doi.org/10.32539/bsm.v5i10.358

\begin{abstract}
A B S T R A C T
Background. Colorectal cancer is the third commonest malignancy and the second leading cause of cancer death in the world. 5-Fluorouracyl-based chemotherapy is the primary treatment modality for colorectal cancer. Cancer stem cells are known to be responsible for chemotherapy resistance. Lgr5 is a colorectal cancer stem cell marker that is the target gene for Wnt signaling. Lgr5 potentiates the Wnt signaling pathway through inhibition of a regulator that inhibits Wnt signaling. Lgr5 overexpression is associated with a worse prognosis and chemotherapy resistance. This study was aimed to investigate the correlation between Lgr5 expression and 5 FU-based chemotherapy response in stage IV colorectal cancer patients at Dr. Mohammad Hoesin Hospital Palembang. Methods. This study used a correlative analysis study with a retrospective design using secondary data from medical records and paraffin blocks of stage IV colorectal cancer patients who received 5-FU-based chemotherapy from September 2018 to September 2020. The number of samples was 30 subjects consisting of 22 cases of negative responses and eight positive responses. All samples were stained with Lgr5 immunohistochemistry. Data analysis used the contingency coefficient correlation test. Results. Of the 30 research subjects, 20 subjects $(66.7 \%)$ had high Lgr5 expression and ten subjects $(33.3 \%)$ with low Lgr5 expression. Correlation analysis using the contingency coefficient test showed a weak correlation between Lgr5 expression and 5-FU based chemotherapy response with a positive direction, which means the higher the Lgr5 expression, the less response to chemotherapy. Conclusion. There is a weak correlation between Lgr5 expression and 5-FU based chemotherapy response in stage IV colorectal cancer patients at
\end{abstract} dr.Mohammad Hoesin Hospital Palembang.

\section{Introduction}

Colorectal cancer is the third commonest malignancy and the second leading cause of cancer death worldwide after lung cancer. There were approximately 1.85 million new cases and 880,000 deaths in 2018. In the United States, colorectal cancer is the fourth commonest cancer and the second leading cause of death after lung cancer.1,2 In Indonesia, colorectal cancer is the fourth commonest cancer in Indonesia, with an incidence rate of $12.1 \%$ and a mortality rate of $6.9 \%$ of all cancers. ${ }^{3}$

Currently, the management of colorectal cancer includes surgery, radiotherapy, chemotherapy, targeted therapy, and immunotherapy. 5-FU-based chemotherapy is a regimen used in the treatment of colorectal cancer. Combining 5-Fluorouracil, leucovorin, and oxaliplatin (FOLFOX) or irinotecan (FOLFIRI) has increased the therapeutic response rate to $50 \%$. However, the therapeutic response varies from patient to patient. Approximately $50 \%$ of colorectal cancer patients do not respond to chemotherapy, causing the disease to become progressive. Side effects of antineoplastic drugs are unnecessary and become a substantial economic burden. Therefore, it is necessary to look for predictive markers that can help clinicians select patients who can benefit from this chemotherapy regimen accurately.4 Several studies have developed methods to predict the therapeutic respinse of 
colorectal cancer patients to chemotherapy. Several tumor molecular markers that predict the efficacy of 5FU or oxaliplatin have been studied, including mutant TP53, thymidylate synthase (TS) expression, and excision repair cross-complementation group 1 (ERCC1). However, none of these markers can be used clinically because of inconsistent results. Although so far less successful, recent studies have shown that microsatellite instability (MSI) is a promising predictive marker for therapeutic response to 5-FU.5.6

Chemotherapy resistance is one of the problems that hinder the effectiveness of chemotherapy and is responsible for poor treatment outcomes and tumor recurrence. Many studies have concluded that cancer stem cells are believed to be responsible for recurrence and resistance to chemotherapy. Chemotherapy can effectively kill cancer cells but has a limited effect on cancer stem cells. Some cancer stem cells survive in a quiescent state and reenter the cell cycle to differentiate, leading to recurrence.

Colorectal cancer stem cells (SPK) were identified through a group of surface markers, including CD133, CD44, CD166, Lgr5, ALDH1, and EpCAM. CD133 as a marker for colorectal cancer was the first to be identified, showing that CD133 expression is not only limited to cancer stem cells but can also be detected in most tumor cells. Leucine-rich repeat-containing Gprotein-coupled receptor 5 (Lgr5) is a surface receptor expressed in the crypt base of the colon and is the target gene of the Wnt signaling pathway. The Wnt signaling pathway plays a role in cell differentiation and growth of colorectal cancer. More than 90\% of colorectal cancers have mutations in the Wnt pathway, especially mutations in the Wnt antagonist Adenomatous Polyposis Coli (APC). Lgr5 potentiates the Wnt signaling pathway through inhibition of a regulator that inhibits Wnt signaling. The consequences of hyperactive Wnt signaling will activate downstream Wnt target molecules such as c-Myc, cyclin D1, survivin, and others. Increased expression of Lgr5 represents one of the molecular changes found in Wnt signaling of colorectal cancer stem cells.

In many studies, Lgr 5 overexpression is associated with poor prognosis in colorectal cancer patients. The meta-analysis study conducted by Chen et al. (2014) in 1883 patients, Jiang et al. (2016) in 2600 patients, and Gzil et al. (2020), who used immunohistochemistry to investigate the association between Lgr5 expression and survival, showed that high Lgr5 expression was associated with shorter overall survival in colorectal cancer patients. Likewise with the research of Takahashi et al. using PCR got the same results. ${ }^{17,24}$

This study attempted to assess the correlation between Lgr5 expression and the response to 5-FUbased chemotherapy in stage IV colorectal cancer patients at Mohammad Hoesin Hospital Palembang. The results of this study are expected that Lgr 5 can be used as a predictor marker in colorectal cancer patients receiving 5-FU-based chemotherapy so that it can be a guide for clinicians to identify which patients will benefit from 5-FU-based chemotherapy treatment.

\section{Methods}

This study used a correlative analytic observational method with a retrospective design. The research was conducted at the Department of Internal Medicine and the Diagnostic Center for Anatomic Pathology, dr. Mohammad Hoesin hospital, Palembang, Indonesia, starting from October 2020 to February 2021. The research subjects (30 people) used secondary data from medical records and paraffin blocks of stage IV colorectal cancer patients who received 5-FU-based chemotherapy in 6 series starting from September 2018 to September 2020 that meet the inclusion criteria. Inclusion criteria: patients aged 18 years to < 80 years, stage IV colorectal cancer patients whose diagnosis was confirmed based on histopathological results from resection or biopsy and abdominal CT scan, patients had received 5-FU-based chemotherapy in 6 series with FOLFOX or FOLFIRI regiment.

Stage IV colorectal cancer is a neoplasm on the surface epithelium of the colon starting from the ascending colon to the rectum that has metastasized to one or more organs. In this study, metastases were selected in intra-abdominal organs such as liver, kidney, bladder, peritoneum and uterus. Lgr5 expression displays surface markers of colorectal cancer stem cells using Lgr5 antibodies thet xyere 
examined using immunohistochemical techniques. Assessment of Lgr5 immunoexpression was assessed by counting the distribution of the number of positive cells added with intensity (the area of tumor cells colored brown). Tumor cells were Lgr5 positive when stained brown on the cell membrane and cytoplasm. Distribution values $1-3(1=10 \%, 2=11-50 \%, 3=>50 \%)$. Intensity value 1 =light brown, 2 =brown 3 =dark brown). The two scores are added up in a range of 0-6. Criteria for low Lgr5 expression, if it has a value of $3, \operatorname{Lgr} 5$ expression is high if it has a value of 4-6.

Chemotherapy response is a reduction in tumor mass which is assumed to represent the sensitivity of all tumor cells after six series of chemotherapy were given. The chemotherapy response is divided into two, namely; Positive response to therapy: When the response to therapy in the form of complete remission and partial remission. A negative response to therapy: If the response to therapy is in stable disease and progressive disease. Evaluation of chemotherapy response using RECIST version 1.0. Evaluation of target lesions (measurable lesions); Complete response (CR): complete loss of the target lesion. Partial response (PR): Reduced total number of target lesions by $30 \%$ compared to previous imaging. Progressive disease (PD): An increase in the longest diameter of the target lesion by $20 \%$ or detecting a new lesion. Stable disease (SD): Does not meet the PR or PD criteria. Evaluation of non-target lesions (lesions that cannot be measured); Complete response (CR): The loss of all non-target lesions and normal tumor markers; Noncomplete response: The presence of one or more non-target lesions and tumor markers above normal limits; Progressive disease: the addition of a pre-existing nontarget lesion. 5-FU based chemotherapy: Combination regimen consisting of: FOLFOX 4: Oxaliplatin 85 $\mathrm{mg} / \mathrm{m} 2$, Leucovorin 200mg/m2, 5-FU 400 mg/m2 bolus followed by $5-\mathrm{FU} 600 / \mathrm{m} 2$ continuous infusion. FOLFOX 6: Oxaliplatin $85 \mathrm{mg} / \mathrm{m}$, leucovorin 400 $\mathrm{mg} / \mathrm{m} 2,5-\mathrm{FU} 400 \mathrm{mg} / \mathrm{m} 2$ bolus followed by 5-FU 2400 $\mathrm{mg} / \mathrm{m} 2$ continuous infusion. FOLFIRI: Irinotecan 180mg/m2, leucovorin $400 \mathrm{mg} / \mathrm{m} 2,5-\mathrm{FU} 400 \mathrm{mg} / \mathrm{m} 2$ bolus followed by $5-\mathrm{FU} 2400 \mathrm{mg} / \mathrm{m} 2$ continuous infusion.

Data from the acceptance sample were carried out by univariate analysis, bivariate analysis, and multivariate analysis. Univariate analysis to see the baseline characteristics of research subjects. Bivariate analysis was carried out on two main research variables: the correlation of Lgr5 expression with chemotherapy response factors in stage IV colorectal cancer patients using the contingency coefficient correlation test. Variables that in the bivariate analysis have $\mathrm{p}$-value $<0.25$ were tested by multivariate logistic regression test.

\section{Results}

Of the 30 samples that met the inclusion criteria, the highest number of research subjects was in the age group $>50$ years, as many as 16 subjects $(53.3 \%)$ with an average age of $47.13 \pm 11.52$. The age of the lowest subject is 19 years, and the highest is 67 years. Based on gender, the number of male subjects was 16 (53.3\%) and female 14 subjects (46.3\%). In this study, the most common tumor locations were in the left colon, namely 18 study subjects (60\%). Based on the degree of differentiation and histopathological subtype, poor differentiation (63.4\%) and adenocarcinoma subtype $(66.0 \%)$ were the most common. Clinical staging uses the TNM system. where the depth of invasion (T) and lymph node involvement were mostly T3 and T4 as many as 19 subjects (63.4\%) and N1 and N2 as many as 15 subjects (54.55\%). Furthermore, for metastases location, the liver was the most common location for metastases, namely 23 subjects (76.8\%). Based on the results of 6 series of post-chemotherapy CEA levels, most of the CEA levels were still above normal (90\%).

Table 1. Clinical and pathological characteristics of study subjects 


\begin{tabular}{|c|c|c|}
\hline Characteristics & Total & Percentage \\
\hline \multicolumn{3}{|l|}{ Age } \\
\hline - $\quad<50$ y.o. & 14 & 46,7 \\
\hline - $\quad \geq 50$ y.o. & 16 & 53,3 \\
\hline \multicolumn{3}{|l|}{ Gender } \\
\hline - Male & 16 & 53,3 \\
\hline - Female & 14 & 46,7 \\
\hline \multicolumn{3}{|l|}{ Tumor location } \\
\hline - Right colon & 12 & 40,0 \\
\hline - Left colon & 18 & 60,0 \\
\hline \multicolumn{3}{|l|}{ Differentiated stage } \\
\hline - Good & 2 & 6,6 \\
\hline $\begin{array}{ll}\text { - } & \text { Medium } \\
\text { Poor }\end{array}$ & $\begin{array}{r}9 \\
19\end{array}$ & $\begin{array}{l}30,0 \\
63,4\end{array}$ \\
\hline \multicolumn{3}{|l|}{ Tumor histopathology } \\
\hline $\begin{array}{l}\text { - Adenocarcinoma } \\
\text { - Signet ring cell } \\
\text { - Mucinous } \\
\text { T degree }\end{array}$ & $\begin{array}{l}20 \\
3 \\
7\end{array}$ & $\begin{array}{l}66,6 \\
10,0 \\
23,4\end{array}$ \\
\hline - $\mathrm{T} 1-\mathrm{T} 2$ & 11 & 36,6 \\
\hline - $\quad \mathrm{T} 2-\mathrm{T} 3$ & 19 & 63,4 \\
\hline \multicolumn{3}{|l|}{$\mathrm{N}$ degree } \\
\hline - $\quad$ NO & 7 & 23,3 \\
\hline $\begin{array}{l}\quad \mathrm{N} 1-\mathrm{N} 2 \\
\mathrm{Nx}\end{array}$ & $\begin{array}{r}15 \\
8\end{array}$ & $\begin{array}{l}50,0 \\
26,7\end{array}$ \\
\hline \multicolumn{3}{|l|}{$\begin{array}{l}\text { Metastasis location } \\
\quad \text { Liver }\end{array}$} \\
\hline - Kidney & 23 & 76,8 \\
\hline - $\quad$ Peritoneal & 2 & 6,6 \\
\hline - Vesica urinaria & 2 & 6,6 \\
\hline - $\quad$ Prostate & 1 & 3,3 \\
\hline - Uterus & 1 & 3,3 \\
\hline CEA level after 6-series chemotherapy & 1 & 3,3 \\
\hline - $\quad<5(\mathrm{ng} / \mathrm{mL})$ & 3 & 10,0 \\
\hline - $\quad \geq 5(\mathrm{ng} / \mathrm{mL})$ & 27 & 90,0 \\
\hline
\end{tabular}

Confounding variables need to be tested before looking for the relationship between Lgr5 expression and chemotherapy response. Tumor intrinsic factors such as age, gender, tumor location, degree of differentiation, tumor histopathology, and depth of tumor invasion play a role in predicting the success of chemotherapy. Of the six variables analyzed, there was no significant relationship between clinicopathological factors and the response to chemotherapy. 


\begin{tabular}{|c|c|c|c|c|c|c|}
\hline \multirow{2}{*}{ Characteristics } & \multicolumn{2}{|c|}{ Response } & \multirow[b]{2}{*}{$\mathrm{P}$} & \multicolumn{2}{|c|}{ Expression } & \multirow[b]{2}{*}{$\mathrm{p}$} \\
\hline & $\begin{array}{c}\text { Negative } \\
\mathrm{n}(\%) \\
\end{array}$ & $\begin{array}{l}\text { Positive } \\
\mathrm{n}(\%) \\
\end{array}$ & & $\begin{array}{l}\text { High } \\
\mathrm{n}(\%) \\
\end{array}$ & $\begin{array}{l}\text { Low } \\
\mathrm{n}(\%) \\
\end{array}$ & \\
\hline Age & & & 0,82 & & & 0,122 \\
\hline & $\begin{array}{l}10 \\
(45,5)\end{array}$ & $4(50,0)$ & & $7(35,0)$ & $7(70,0)$ & \\
\hline - $\quad \geq 50$ y.o. & $\begin{array}{l}12 \\
(54,5)\end{array}$ & $4(50,0)$ & & $13(65,0)$ & $3(30,0)$ & \\
\hline Gender & & & $\begin{array}{c}0,68 \\
9\end{array}$ & & & 0,709 \\
\hline - Male & $\begin{array}{l}11 \\
(50,0)\end{array}$ & $5(62,5)$ & & $10(50,0)$ & $6(60,0)$ & \\
\hline - Female & $\begin{array}{l}11 \\
(50,0)\end{array}$ & $3(37,5)$ & & $10(50,0)$ & $4(40,0)$ & \\
\hline Tumor location & & & $\begin{array}{c}0,21 \\
0\end{array}$ & & & 0,139 \\
\hline - $\quad$ Right colon & $\begin{array}{c}7 \\
(31,8)\end{array}$ & $5(62,5)$ & & $6(30,0)$ & $6(60,0)$ & \\
\hline - $\quad$ Left colon & $\begin{array}{l}15 \\
(68,2)\end{array}$ & $3(37,5)$ & & $14(70,0)$ & $4(40,0)$ & \\
\hline Tumor differentiation & & & $\begin{array}{c}0.19 \\
9\end{array}$ & & & 0,246 \\
\hline - High degree & $\begin{array}{l}12 \\
(54,6)\end{array}$ & $7(87,5)$ & & $11(55,0)$ & $8(80,0)$ & \\
\hline - Low degree & $\begin{array}{l}10 \\
(45,4)\end{array}$ & $1(12,5)$ & & $9(45,0)$ & $2(20,0)$ & \\
\hline Tumor histopathology & & & $\begin{array}{c}0,14 \\
2\end{array}$ & & & $0,027^{*}$ \\
\hline - Adenocarcinoma & 16 & $4(50,0)$ & & $17(85,0)$ & $3(30,0)$ & \\
\hline - Signet ring cell & $(72,8)$ & $0(0,00)$ & & $0(0,00)$ & $3(30,0)$ & \\
\hline - Mucinous & & $4(50,0)$ & & $3(15,0)$ & $4(40,0)$ & \\
\hline $\mathrm{T}$ degree & $\begin{array}{c}3 \\
(13,6)\end{array}$ & & $\begin{array}{c}0,41 \\
7\end{array}$ & & & 0,284 \\
\hline - $\quad \mathrm{T} 1-\mathrm{T} 2$ & $\begin{array}{c}7 \\
(31,8)\end{array}$ & $4(50,0)$ & & $6(30,0)$ & $6(60,0)$ & \\
\hline - $\quad \mathrm{T} 3-\mathrm{T} 4$ & $\begin{array}{l}15 \\
(68,2)\end{array}$ & $4(50,0)$ & & $14(70,0)$ & $4(40,0)$ & \\
\hline
\end{tabular}

Statistical analysis with Chi square test and Fischer exact test

This study also analyzed the relationship of several clinicopathological factors to the distribution of Lgr5 expression, including age, gender, tumor location, degree of differentiation, tumor histopathology, and depth of invasion. The clinicopathological picture based on the degree of Lgr5 expression showed that the research subjects aged 50 years were primarily found in the high Lgr 5 expression group. In contrast, in the $<50$ year age group, the low Lgr 5 expression group was the most. For the gender factor, male and female subjects in the high Lgr5 expression group were the most numerous with the same amount, while the most male subjects were found in the low Lgr5 expression group. The study subjects with the most left colon location were found in the high Lgr5 expression group for tumor location, while the right colon location was mainly found in the low Lgr 5 expression group.

The highest degree of differentiation was found in the high Lgr5 expression and low Lgr5 expression groups based on the degree of tumor differentiation. For the depth of tumor invasion, the most T3-T4 grades were found in the high Lgr 5 expression group, while the T1-T2 grades were the most in the low Lgr5 expression group. From the comparison results of several clinicopathological factors above in the high Lgr5 expression group and low Lgr 5 expression group, after a comparative analysis was carried out in the two groups using the Fisher exact test, there was no significant relationship between the two groups ( $p>$ 0.05). 
Based on tumor histopathology, adenocarcinoma was most commonly found in the group with high Lgr5 expression. Meanwhile, mucinous and signet ring cells were found in the low Lgr5 expression group. From the

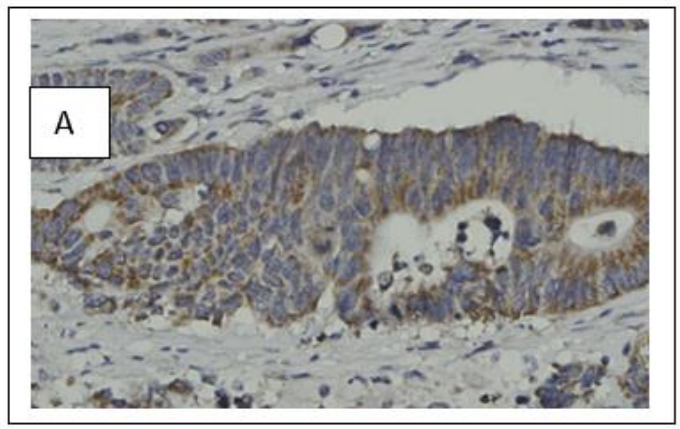

Figure 1. (A)High Lgr5 expression; (B) Low Lgr5 expression. results of the comparative analysis, there was a significant relationship between the two groups $(\mathrm{p}=$ 0.027).

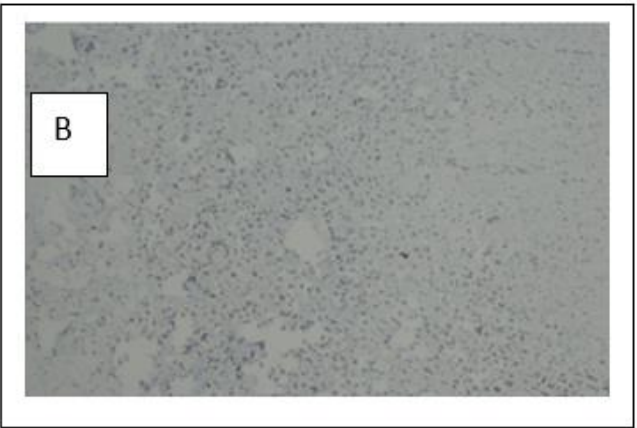

$(62.5 \%)$ and three subjects $(37.5 \%)$. The contingency coefficient correlation test results showed a significant correlation between the expression of Lgr5 and the response to chemotherapy with a $\mathrm{p}$-value $=0.042$. The correlation coefficient shows a weak relationship strength $(r=0.373)$ and in a positive direction. subjects with high and low Lgr5 expression in the group that responded positively were five subjects

Table 3. Correlation of Lgr5 expression of research subjects to chemotherapy response.

\begin{tabular}{ccccc}
\hline Lgr5 expression & Negative response & Positive response & $* p$ & $r$ \\
& & & & \\
\hline High & $17(77,3)$ & $3(37,5)$ & 0,042 & 0,373 \\
Low & $5(22,7)$ & $5(62,5)$ & &
\end{tabular}

${ }^{*}$ Contingency coefficient correlation test

Value of $\mathrm{r}=0.00$ to $<0.2$; very weak, $\mathrm{r}=0,2 \mathrm{sd}<0,4$; weak, $\mathrm{r}=0,4 \mathrm{sd}<0,6$; medium, $\mathrm{r}=0.6$ to $<0.8$ strong; $\mathrm{r}=0.8$ to 1 ; very strong.

Multivariate analysis was conducted to determine the risk factors for chemotherapy response clinically and statistically. From the results of multivariate analysis using logistic regression analysis, it was found that tumor location, degree of differentiation, and tumor histopathology were not related to chemotherapy response $(\mathrm{p}>0.05)$. 


\begin{tabular}{|c|c|c|c|c|c|c|c|c|}
\hline \multirow{2}{*}{ Variables } & \multirow{2}{*}{$\mathrm{B}$} & \multirow{2}{*}{$\mathrm{SE}$} & \multirow{2}{*}{ Wald } & \multirow{2}{*}{$\mathrm{df}$} & \multirow{2}{*}{ *p } & \multirow{2}{*}{ OR } & \multicolumn{2}{|c|}{ IK 95\% } \\
\hline & & & & & & & Min & $\operatorname{Max}$ \\
\hline $\begin{array}{l}\text { Tumor location } \\
3,214\end{array}$ &,- 728 &,- 967 & &, 566 & 1 & 0.452 & 0.483 & 0.073 \\
\hline $\begin{array}{l}\text { Diferentiation } \\
\text { Tumor }\end{array}$ & $\begin{array}{l}1,499 \\
39,568\end{array}$ & 1,194 & 1,574 & 1 & & 0,374 & 3,140 & 0,249 \\
\hline histopathology & $\begin{array}{c}, 798 \\
13.905\end{array}$ & ,936 & ,720 & 1 & & 0,394 & 2,221 & ,355 \\
\hline
\end{tabular}

\section{Discussion}

This study focused on the relationship between Lgr5 expression and chemotherapy response in stage IV colorectal cancer patients. Based on the results of the study, it appears that the higher the expression of Lgr5, the less response to 5-FU-based chemotherapy. In addition, the statistical analysis showed a significant correlation with weak strength between Lgr5 expression and 5-FU-based chemotherapy response. Research by Hsu et al. (2013) conducted a study on 64 stage IV colorectal cancer patients found that $73 \%$ did not respond to chemotherapy with high Lgr5 expression compared to $27 \%$ in low Lgr5 expression. From the results of statistical tests, it was found that there was a significant relationship between the response to therapy and the expression of Lgr5 $(p=0.025)$. No independent predictive factors on response to therapy were found in this study which is the same as in this study.25,26

Research by Xi et al. (2014) also reported similar results in 68 gastric cancer patients who received adjuvant chemotherapy. Increased expression of Lgr5 in gastric cancer was significantly associated with inadequate pathological response to $5 \mathrm{FU}$-based chemotherapy $(\mathrm{p}=0.001) .27$

The mechanism of resistance of cancer stem cells to $5 F U$ chemotherapy is thought to be through antiapoptotic mechanisms, increased DNA repair, and drug transporters. High expression of Lgr5 will increase free catenin levels and enter the nucleus, resulting in increased expression of target genes such as survivin and MDR2. Survivin is a member of the antiapoptotic protein family that regulates cell cycle development and cell survival. The presence of survivin indicates that the cells are in a pluripotent phase which undergoes a selfrenewal process. This is a hallmark of cancer stem cells. The research of Tamm et al. (1998) stated that an increase in survivin expression would inhibit caspase9 and effector caspase so that cells could survive apoptosis and even continue to proliferate. 28,29

Research by Cho et al. (2020) stated that p53, whose the main route for the anticancer effect of $5-\mathrm{FU}$, has a crucial role in inhibiting proliferation through apoptosis. Activation of the p53 signaling pathway is one of the responses of cancer cells to DNA damage caused by $5-\mathrm{FU}$. Research conducted by Wang et al. (2004) stated that survivin works to increase the inhibition of Mdm2 protein degradation (Mouse double minute 2 homolog). An increase in Mdm2 will increase the degradation of p53 and ultimately result in a decrease in the level of p53 protein in cells. Decreased p53 expression causes the carcinogenesis process to run without control by p53. This is due to the inactivation of $\mathrm{p} 21$, which is a strong inactivator of the cyclin-CDK complex, which causes the cell cycle not to stop so that cell proliferation will continue. In addition, the decrease in p53 increased the amount of prosurvival protein BCL 2 and consequently inhibited the proapoptotic proteins BAX and BAK. This process inhibits the release of cytochrome $\mathrm{C}$ from the mitochondria, inhibits the formation of apoptosomes, and causes cells to survive apoptosis and even continue to proliferate. 30

Increased expression of Lgr5 will also increase the expression of drug transporters such as p-glycoprotein to remove anticancer substrates such as 5-FU from cells, resulting in a decrease in intracellular concentrations of these substrates and capzses; 
resistance to chemotherapy. Research by Liu et al. (2013) reported that Lgr5 expression depletion would decrease p-glycoprotein expression. Lgr5 plays a role in regulating $\mathrm{p}$-glycoprotein expression through the Wnt pathway. 31,32

\section{Conclusion}

There is a weak correlation between Lgr 5 expression and chemotherapy response of stage IV colorectal cancer patients at dr. Mohammad Hoesin Hospital, Palembang.

\section{References}

1. International Agency for Research on Cancer, World Health Organization, Globocan 2018.

2. American Cancer Society. Colorectal cancer, facts and figures 2014-2016, Atlanta. 2014.

3. Carrato A. Adjuvant treatment of colorectal cancer. Gastroint Cancer Res 2018, 2; 42-6.

4. Lu W, Fu D, Kong X et al. FOLFOX treatment response prediction in metastatic or recurregł4 colorectal cancer patients via machine learining algorithms. Cancer Med 2020; 9: 1419-29.

5. Choueri M, Shen J, Cross A et al. ERCC1 and TS expression as prognostic and predictive biomarkers in metastatic colon cancer. PLoS One 2015, 10: 60-8.

6. Van der Jeught $\mathrm{K}, \mathrm{Xu} \mathrm{H}, \mathrm{Li} \mathrm{Y}$ et al. Drug resistance and new therapies in colorectal cancer. World J Gastroenterol 2018, 24: 383448.

7. Hu T, Li Z, Gao C, Go C et al. Mechanisms of drug resistance in colon cancer and its therapeutic strategies. World J Gastroenterol 2016, 22: 6876-89.

8. Phi L, Sari IN, Yang Y et al. Cancer stem cells in drug resistance and their therapeutic implications in cancer treatment. Stem Cell Int 2018, 1-16.

9. Abdullah L, Chow E. Mechanisms of chemoresistance in cancer stem cells. Clin Transl Med 2013, 2: 1-10.

10. Zhou Y, Xia L, Wang H et al. Cancer stem cells in progression of colorectal cancer. Oncotarget.
2018 ; 9: 33403-15.

11. Becker L, Huang Q, Mashimo $H$ et al. Immunostaining of Lgr5, an intestinal stem cell marker, in normal and premalignant human gastrointestinal tissue. Sci World J 2008, 8: 1168-76.

12. Ducharte Y, Kim YM, Kan M et al. The Wnt signaling pathway in cancer. Crit Rev Onc Hematol 2016, 99:141-9.

13. Clevers $H$. Wnt/ $\beta$-catenin signaling and disease. Cell 2012, 149: 1192-205.

14. Kumar K, Burgess A, Gulbis J. Structure and function of LGR5: An enigmatic G-protein coupled receptor marking stem cells. Protein Sci 2014, 23: 551-65.

15. Xu L, Lin W, Li G et al. Lgr5 in cancer biology: functional identification of Lgr5 in cancer progression and potential opportunities for novel therapy. Stem Cell Res Ther 2019, 10:19.

16. Chen Q, Zhang X, Zheng P et al. Prognostic Value of LGR5 in Colorectal Cancer: A MetaAnalysis. PLoS One 2014, 9: 1-9.

17. Jiang Y, LI W, He X et al. Lgr5 expression is a valuable prognostic factor for colorectal cancer. BMC Cancer 2015; 15: 1-10.

18. Gzil A, Zabreska I, Jaworsky D. The prognostic value of leucine-rich repeat-containing Gprotein (Lgr5) and its impact on clinicopathological features of colorectal cancer. J Cancer Res Clin Oncol 2020, 146: 2547-57.

19. Takahashi $\mathrm{H}$, Ishii $\mathrm{H}$, Nishida $\mathrm{N}$ et al. Significance of Lgr5(+ve) cancer stem cells in the colon and rectum. Ann Surg Oncol 2011, 18: $1166-74$.

20. Hsu H, Liu Y, Tseng K et al. Overexpression of Lgr5 correlates with resistance to 5-FU-based chemotherapy in colorectal cancer. Int $\mathrm{J}$ Colorectal Dis 2013, 28: 1535-46.

21. Xi H, Cui J, Shen W et al. Increased expression of Lgr5 is associated with chemotherapy resistance in gastric cancer. Oncol Rep 2014;32:181-188. 
22. Zhang J. LGR5, a novel functional glioma stem cell marker, promotes EMT by activating the Wnt/beta-catenin pathway and predicts poor survival of glioma patients. J Exp Clin Cancer Res. 2018, 37: 225.

23. Stanisavljevic L, Leh S, Dahl O et al. LGR5 and CD133 as prognostic and predictive markers for fluoropyrimidine-based adjuvant chemotherapy in colorectal cancer. Acta Oncol 2016, 55:1425-33.

24. $\mathrm{Xi} \mathrm{H}$ et al. Increased expression of $\operatorname{Lgr} 5$ is associated with chemotherapy resistance in human gastric cancer. Oncol Rev 2014, 32:181-8.

25. Sato K, Uehara T, Iwaya M et al. Correlation of clinicopathological features and LGR5 expression in colon adenocarcinoma. Ann Diagn Pathol 2019; 40: 161-5.

26. Saigusa S, Tanaka K, Hiro J et al. Clinical significance of LGR5 and CD44 expression in locally advanced rectal cancer attes75 preoperative chemoradiotherapy. Int J Orıcó1 2012; 41: 1643-52.

27. Zheng $Z$, Yu H, Fan $\mathrm{X}$ et al. Heterogeneous expression of Lgr5 as a risk factor for focal invasion and distant metastasis of colorectal carcinoma. Oncotarget 2018;10; 25-33 .

28. Amsterdam A. Differentiallocalization of LGR5 and Nanog in clusters of colon cancer stem cells. Acta Histochem 2013, 115:320-9.

29. Nakajima $T$, Uehara $T$, Ota $H$ et al. Characterization of LGR5 expression in poorly differentiated colorectal carcinoma with mismatch repair protein deficiency. BMC Cancer 2020; 319: 1-12.

30. Su S, Hong F, Zhou J et al. Lgr5 Methylation in cancer stem cell differentiation and prognosis-prediction in colorectal cancer. PLoS One $2015 ; 24 ; 10-20$.

31. Rosiq S, Anas A, Amer M et al. Colonic stem cells expression of Lgr5 and CD133 proteins as predictive markers in colorectal cancer among Egyptian patients. Open Access Maced J Med Sci 2018, 6: 968-74.
32. Cho Y, Ro R, So $J$ et al. 5-FU promotes stemness of colorectal cancer via p53-mediated WNT/ $\beta$-catenin pathway activation. Nature Comm 2020; 11: 532-40. 